\section{Medical adherence in the time of social distancing: a brief report on the impact of the COVID-19 pandemic on adherence to treatment in patients with diabetes}

\author{
Debora Wilke Franco ${ }^{1,2}$ \\ https://orcid.org/0000-0001-8531-8445 \\ Janine Alessi $i^{3}$ \\ https://orcid.org/0000-0003-4311-3307
}

Alice Scalzilli Becker ${ }^{2}$

https://orcid.org/0000-0003-0781-590X

Bibiana Brino do Amaral ${ }^{2}$

https://orcid.org/0000-0001-5561-9378

Giovana Berger de Oliveira ${ }^{2}$

https://orcid.org/0000-0001-8071-9741

Beatriz D. Schaan $3,4,5$

https://orcid.org/0000-0002-2128-8387

Gabriela Heiden Telo $1,2,6$

https://orcid.org/0000-0001-9093-383X

\section{ABSTRACT}

We conducted a cross-sectional study to evaluate the impact of social distancing determined by the COVID-19 pandemic on treatment adherence using the Self-Care Inventory-revised in adults with diabetes mellitus. In type 1 diabetes, the adherence score was lower during than before social distancing. Arch Endocrinol Metab. 2021;65(4):517-21

Keywords

Medical adherence; COVID-19 pandemic; diabetes mellitus; adherence to treatment; social distancing
1 Programa de Pós-graduação em Medicina e Ciências da Saúde, Pontifícia Universidade Católica do Rio Grande do Sul, Porto Alegre, RS, Brasil

${ }^{2}$ Escola de Medicina, Pontifícia Universidade Católica do Rio Grande do Sul, Porto Alegre, RS, Brasil ${ }^{3}$ Programa de Pós-Graduação em Ciências Médicas: Endocrinologia, Universidade Federal do Rio Grande do Sul, Porto Alegre, RS, Brasil

${ }^{4}$ Escola de Medicina, Universidade Federal do Rio Grande do Sul,

Porto Alegre, RS, Brasil

${ }^{5}$ Divisão de Endocrinologia, Hospital de Clínicas de Porto Alegre, Porto Alegre, RS, Brasil

${ }^{6}$ Departamento de Medicina

Interna, Hospital São Lucas,

Pontifícia Universidade Católica do

Rio Grande, Porto Alegre, RS, Brasil

Correspondence to:

Debora Wilke Franco

Universidade Pontifícia Católica do

Rio Grande do Sul

Av. Ipiranga, 6.681, prédio $12,2^{\circ}$

andar - 90619-900 - Porto Alegre,

RS, Brasil

debora.franco@edu.pucrs.br

Received on Sept/20/2020 Accepted on Feb/18/2021

DOI: 10.20945/2359-3997000000362

\section{INTRODUCTION}

$\mathrm{T}$ reatment adherence is the main factor in the management of hyperglycemia and, consequently, in the reduction of diabetes-related complications. Stressful events have a significant impact on treatment adherence in patients living with diabetes mellitus, and the COVID-19 pandemic provides further reason for concern about these patients, who are among those at highest risk (1-5). In recent months, Brazil has become one of the pandemic epicenters in the world, with approximately 2,100,000 confirmed cases so far (6). This scenario may directly impact diabetes care due to poor availability of medical appointments, increased difficulty in obtaining medications, and home isolation.

The intrinsic differences in type of diabetes may impact patients with type 1 and type 2 diabetes differently during the pandemic. While spending more time at home could facilitate proper adherence to treatment guidelines, maintaining healthy eating habits and exercising may be challenging during quarantine. Therefore, the present study aimed to evaluate adherence in a cohort of patients with type 1 and type 2 diabetes during social distancing.

\section{METHODS}

\section{Study design and setting}

We conducted a controlled cross-sectional study to evaluate aspects of treatment adherence in a cohort of patients with type 1 and type 2 diabetes during social distancing. We invited patients to participate in the study by phone calls, during which the informed consent form was read aloud and any questions from potential participants were answered or clarified. 
Each patient's informed consent was documented through audio recording. We administered a specific questionnaire to evaluate treatment adherence 1 month after the publication of the national recommendation of social distancing for high-risk groups for COVID-19 in Brazil.

\section{Participants}

We selected patients under regular monitoring at the endocrinology outpatient clinic of a tertiary public hospital in southern Brazil and divided them into 2 groups: social distancing group and control group. The inclusion criteria were previous diagnosis of type 1 or type 2 diabetes, age $\geq 18$ years, HbAlc measured 3 months prior to inclusion in the study, and updated contact information in the electronic database. We excluded patients with any physical or cognitive impairment that could limit questionnaire administration and those who were hospitalized at the time of recruitment. For the social distancing group, we also excluded patients who were not following other social distancing rules besides the current national recommendation for high-risk groups. For the control group, we selected patients from 2 previous cohorts designed to evaluate treatment adherence before the pandemic. The data were collected in 2014 for the type 1 diabetes control group and in 2016 for the type 2 diabetes control group. Patients in the social distancing and control groups were matched for age for the present study.

\section{Study outcome}

We used a validated Brazilian Portuguese version of the Self-Care Inventory-revised (SCI-R) (7-8) to evaluate treatment adherence before and during the pandemic. We asked participants to answer the 14 questions with frequency descriptors. A score of 1 to 5 is assigned to each item, and a final score ranging from 14 to 70 is then calculated. Higher scores indicate greater adherence to diabetes treatment.

\section{Clinical variables}

We collected demographic and clinical variables from medical records and confirmed the data during the study telephone evaluation.

\section{Sample size}

Considering an estimated $27 \%$ increase in the risk of non-adherence in situations of anxiety and depression and the prevalence of poor adherence described in the literature of $49.1 \%$ in type 1 diabetes and of $42.0 \%$ in type 2 diabetes, we calculated that 110 patients with type 1 diabetes and 150 patients with type 2 diabetes would be needed to perform an analysis with $80 \%$ power and alpha of 0.05 (9-11).

\section{Statistical analysis}

We presented the data as mean (SD), median and interquartile range (IQR), or percentages. We used unpaired $t$ test for continuous variables and $\chi^{2}$ test for categorical variables. We compared the social distancing and control groups using the MannWhitney test for nonparametric data. We stratified the analyses according to type of diabetes. Because the time of evaluation differed between the social distancing group and the control groups, we included a variable called 'calendar year' in a linear regression model to adjust for possible differences related to improvements in diabetes care over time. Considering that the effect of time is expected to be positive on treatment-adherence parameters, the adjustments for calendar year are presented only when the adherence score has increased in the social distancing group, as this group represents the most recently assessed one for diabetes care. We analyzed the data in SPSS, version 20 , and set the level of statistical significance at $\mathrm{p} \leq 0.05$ for all analyses.

\section{Ethical aspects}

The study was approved by the institution's research ethics committee (number 4.029.368) and reported following the STROBE guidelines (12). The project is registered at the Brazilian platform for research involving human participants called Plataforma Brasil (https://plataformabrasil.saude.gov.br/login.jsf), number 30528620.1.0000.5327.

\section{RESULTS}

\section{Characteristics of the participants}

We included 260 participants in the study. Overall, mean age was 43.7 (SD 12.7) years; $45.5 \%$ were female and $97.3 \%$ were white (see Table 1). The social distancing and control groups were similar in terms of demographics and clinical variables. There was also no difference in treatment regimens between the groups. 
Table 1. Demographics and clinical characteristics of study participants

\begin{tabular}{|c|c|c|c|c|}
\hline TYPE 1 DIABETES & $\begin{array}{c}\text { Total } \\
(\mathrm{N}=110)\end{array}$ & $\begin{array}{l}\text { Social distancing group } \\
\qquad(\mathrm{n}=55)\end{array}$ & $\begin{array}{l}\text { Control } \\
(n=55)\end{array}$ & $P$ value \\
\hline Age (years) & $43.7 \pm 12.7$ & $43.4 \pm 13.8$ & $43.9 \pm 11.7$ & 0.81 \\
\hline Sex (\% female) & $45.5 \%$ & $49.1 \%$ & $45.5 \%$ & 0.44 \\
\hline Race/ethnicity (\% white) & $97.3 \%$ & $96.4 \%$ & $98.2 \%$ & 0.22 \\
\hline Age at diabetes diagnosis (years) & $19.2 \pm 11.4$ & $18.4 \pm 12.5$ & $19.9 \pm 10.2$ & 0.47 \\
\hline Diabetes duration (years) & $24.6 \pm 11.4$ & $24.9 \pm 11.8$ & $24.1 \pm 11.0$ & 0.70 \\
\hline HbA1c (\%) & $8.6 \pm 1.6$ & $8.6 \pm 1.5$ & $8.6 \pm 1.8$ & 1.0 \\
\hline$(\mathrm{mmol} / \mathrm{mol})$ & $71.0 \pm 17.9$ & $71.0 \pm 15.9$ & $71.0 \pm 19.7$ & \\
\hline \multicolumn{5}{|l|}{ Diabetes complications } \\
\hline Retinopathy & $48.2 \%$ & $49.1 \%$ & $47.3 \%$ & 0.83 \\
\hline Neuropathy & $17.3 \%$ & $23.6 \%$ & $10.9 \%$ & 0.08 \\
\hline BMl overweigh/obese (\%) & $46.3 \%$ & $45.3 \%$ & $47.3 \%$ & 0.83 \\
\hline Hypertension (\%) & $21.8 \%$ & $25.5 \%$ & $18.2 \%$ & 0.35 \\
\hline Cardiovascular disease (\%) & $11.8 \%$ & $12.7 \%$ & $10.9 \%$ & 0.76 \\
\hline TYPE 2 DIABETES & $(N=150)$ & $(n=75)$ & $(n=75)$ & \\
\hline Age (years) & $61.3 \pm 7.9$ & $61.8 \pm 8.7$ & $60.7 \pm 7.0$ & 0.40 \\
\hline Sex (\% female) & $60.7 \%$ & $63.5 \%$ & $58.7 \%$ & 0.38 \\
\hline Race/ethnicity (\% white) & $74.0 \%$ & $78.4 \%$ & $70.7 \%$ & 0.09 \\
\hline Age at diabetes diagnosis (years) & $43.6 \pm 10.6$ & $42.8 \pm 9.7$ & $44.2 \pm 11.4$ & 0.42 \\
\hline Diabetes duration (years) & $17.6 \pm 9.0$ & $18.8 \pm 9.5$ & $16.5 \pm 8.6$ & 0.12 \\
\hline $\mathrm{HbA1c}(\%)$ & $8.8 \pm 1.5$ & $8.9 \pm 1.5$ & $8.6 \pm 1.5$ & 0.36 \\
\hline (mmol/mol) & $73.0 \pm 16.4$ & $74.0 \pm 16.4$ & $70.0 \pm 16.4$ & \\
\hline \multicolumn{5}{|l|}{ Diabetes complications } \\
\hline Retinopathy & $46.0 \%$ & $43.2 \%$ & $48.0 \%$ & 0.46 \\
\hline Neuropathy & $34.0 \%$ & $29.7 \%$ & $38.7 \%$ & 0.39 \\
\hline Nephropathy & $46.7 \%$ & $44.6 \%$ & $49.3 \%$ & 0.54 \\
\hline Insulin use (\%) & $84.7 \%$ & $89.2 \%$ & $80.0 \%$ & 0.27 \\
\hline BMl overweigh/obese (\%) & $91.0 \%$ & $91.3 \%$ & $90.7 \%$ & 0.94 \\
\hline Hypertension (\%) & $82.6 \%$ & $82.4 \%$ & $82.7 \%$ & 0.89 \\
\hline Cardiovascular disease (\%) & $38.7 \%$ & $41.9 \%$ & $36.0 \%$ & 0.55 \\
\hline
\end{tabular}

Data are presented as mean \pm SD or \%. $\alpha \leq 0.05$ indicates significant difference. HbA1c: hemoglobin A1c; BMl: body mass index.

\section{Outcomes}

In type 1 diabetes, the median SCI-R score was lower in the social distancing group (48.0, IQR 41.0-52.0) than in the control group (52.0, IQR 46.0-54.0) $(\mathrm{p}<0.01)$ (see Figure 1$)$. In type 2 diabetes, the median SCI-R scores were similar in the social distancing (48.0, IQR 43.0-55.0) and control groups (47.0, IQR 44.051.0) $(\mathrm{p}=0.14)$.

\section{DISCUSSION}

This study found no difference in adherence scores among patients with type 2 diabetes before and during social distancing related to the COVID-19 pandemic. Although spending more time at home could facilitate

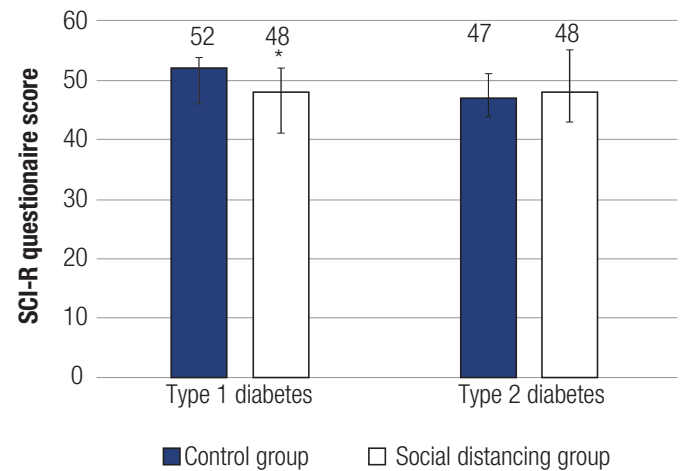

Figure 1. Adherence scores among patients with type 1 and type 2 diabetes before and during social distancing determined by COVID-19.

Data are presented as median and interquartile range. *: $\alpha$ level $\leq 0.05$, indicating significant difference. The validated Brazilian version of the SelfCare Inventory-revised (SCl-R) was used for this evaluation. Scores range from 14 to 70 . Higher scores indicate greater adherence to diabetes treatment. 
proper adherence to treatment guidelines, adherence scores worsened among patients with type 1 diabetes during social distancing.

This study has some limitations. As the study has a cross-sectional design, our results reflect only associations between the pandemic and adherence to diabetes treatment, and not causal relationships. Also, the SCI-R was applied only 1 month after the start of social distancing. Considering that the effects of social distancing on adherence can be time dependent, it is possible that the scores would worsen over time. The SCI-R was originally validated for self-administration; therefore, its administration by telephone could introduce a potential measurement bias. Finally, the difference in the time of questionnaire administration between the social distancing and control groups may also have interfered with the results. Nevertheless, to the best of our knowledge, this is the first study to assess the impact of social distancing on treatment-adherence parameters in diabetes.

Reduced availability of multidisciplinary teams and increased difficulty in obtaining medical care during the pandemic may directly interfere with treatment adherence in the future. In addition, studies have shown an increase in psychological and eating disorders during quarantine, which may have an even greater long-term impact in patients with diabetes, especially by negatively impacting adherence to recommended diabetes self-care behaviors (13-14). Further studies are warranted to better understand the impact of home confinement on adherence parameters in diabetes.

Author contributions: Debora Wilke Franco - conceptualization, methodology, writing-original draft preparation. Janine Alessi - conceptualization, methodology, software, data curation, writing-original draft preparation. Alice S. Becker - methodology, investigation. Bibiana Brino do Amaral - methodology, investigation. Giovana B. de Oliveira - methodology, investigation, writing-original draft preparation. Beatriz D. Schaan - conceptualization, validation, supervision, writing, reviewing and editing. Gabriela H. Telo - conceptualization, data curation, writing-original draft preparation, supervision. We declare that all authors are aware of the submission of this manuscript and have allowed to place their name as authors. Debora W. Franco is the guarantor of this work and, as such, had full access to all the data in the study and takes responsibility for the integrity of the data and the accuracy of the data analysis.

Funding: this study was nanced in part by the Coordenação de Aperfeiçoamento de Pessoal de Nivel Superior Brasil (CAPES) Finance Code 001. This work was conducted with support from Hospital de Clinicas de Porto Alegre, the Graduate Program in Medical Sciences: Endocrinology of Universidade Federal do Rio
Grande do Sul, the School of Medicine of Pontificia Universidade Católica do Rio Grande do Sul, and Hospital São Lucas affiliated with Pontificia Universidade Católica do Rio Grande do Sul. The funders had no role in study design, data collection and analysis, decision to publish, or preparation of the manuscript.

Ethics: the project was approved by the institution's research ethics committee under number 4.029 .368 and all authors signed the term of responsibility for data use.

Prior presentation: no prior presentation of the data presented has been made.

Data sharing: the data collected for the study will be available for 2 years after publication of the article.

Disclosure: no potential conflicts of interest relevant to this article were reported.

\section{REFERENCES}

1. Walders-Abramson N, Venditti EM, Levers-Landis CE, Anderson B, El Ghormli L, Geffner M, et al. Relationships among stressful life events and physiological markers, treatment adherence, and psychosocial functioning among youth with type 2 diabetes. J Pediatr. 2014;165(3):504-8.e1.

2. Pyatak EA, Sequeira $P A$, Whittemore $R$, Vigen $C P$, Peters $A L$, Weigensberg MJ. Challenges contributing to disrupted transition from paediatric to adult diabetes care in young adults with Type 1 diabetes. Diabet Med. 2014;31(12):1615-24.

3. Fadini GP, Morieri ML, Longato E, Avogaro A. Prevalence and impact of diabetes among people infected with SARS-CoV-2. J Endocrinol Invest. 2020;43(6):867-9.

4. SinghA, Gupta R, GhoshA, MisraA. Diabetes in COVID-19: Prevalence, pathophysiology, prognosis and practical considerations. Diabetes Metab Syndr Clin Res Rev J. 2020;14:303-10.

5. Muniyappa R, Gubbi S. COVID-19 pandemic, coronaviruses, and diabetes mellitus. Am J Physiol Endocrinol Metab. 2020;318(5):E736-41.

6. World Health Organization. Coronavirus disease (COVID-19) Situation Report-131. Available from: https://www.who.int/docs/ default-source/coronaviruse/situation-reports/20200530-covid19-sitrep-131.pdf?sfvrsn=d31ba4b3_2. Accessed in: May 30, 2020.

7. Teló GH, De Souza MS, Schaan BDA. Cross-cultural adaptation and validation to Brazilian Portuguese of two measuring adherence instruments for patients with type 1 diabetes. Diabetol Metab Syndr. 2014;6(141):1-6.

8. Teló GH, lorra FQ, Velho BS, Sparrenberger K, Schaan BD. Validation to Brazilian Portuguese of the self-care inventoryrevised for adults with type 2 diabetes. Arch Endocrinol Metab. 2020;64(2):190-4.

9. DiMatteo MR. Variations in patients' adherence to medical recommendations: A quantitative review of 50 years of research. Med Care. 2004;42(3):200-9.

10. Maoui A, Bouzid K, Abdelaziz A, Abdelaziz A. Epidémiologie du Diabète de Type 2 au Grand Maghreb. Exemple de la Tunisie. Revue systématique de la littérature. J la Société Tunisienne des Sci Médicales. 2019;97(02):286-95.

11. Almeda-Valdes $\mathrm{P}$, Ríofrio JP, Coronado KWZ, de la Parra DR, Cabrera JB, Gómez-Pérez FJ, et al. Factors Associated with Insulin Nonadherence in Type 1 Diabetes Mellitus Patients in Mexico. Int J Diabetes Metab. 2019;14080(15):1-9. 
12. Gharaibeh A, Koppikar S, Bonilla-Escobar FJ. Strengthening the Reporting of Observational Studies in Epidemiology (STROBE) in the International Journal of Medical Students. Int J Med Students. 2014;2(2):36-7.

13. Brooks SK, Webster RK, Smith LE, Woodland L, Wessely S, Greenberg N, et al. The psychological impact of quarantine and how to reduce it: rapid review of the evidence. Lancet. 2020;395(10227):912-20.

14. Vindegaard N, Benros ME. COVID-19 pandemic and mental health consequences: Systematic review of the current evidence. Brain Behav Immun. 2020;89:531-42. 